\title{
EUROPA EN CASTILLA: OBISPOS DIPLOMÁTICOS Y ARQUITECTURA DEL TARDOGÓTICO
}

\author{
EUROPE IN CASTILE: BISHOP-DIPLOMATS \\ AND LATE GOTHIC ARCHITECTURE
}

\author{
BEgOÑA AlONSO RUIZ \\ Universidad de Cantabria \\ https://orcid.org/0000-0002-5062-6998
}

\begin{abstract}
Resumen: La renovación del siglo XV castellano ha sido relacionada en diversas ocasiones con la labor de determinados prelados y sus misiones diplomáticas por Centroeuropa o Flandes, del mismo modo que la llegada del Renacimiento a Castilla aparece inexorablemente unida a otras figuras de diplomáticos en Italia. Nos ocupamos en estas páginas de varios obispos que visitaron centros artísticos europeos como diplomáticos, a la vez que desarrollaron una importante actividad como promotores artísticos. Nos interesa preguntarnos en este estado de la cuestión acerca de cómo pudo ayudar el viaje en sus encargos y cómo esos lenguajes de fuera pudieron $-\mathrm{o}$ no- reflejarse en sus promociones artísticas, especialmente en las arquitectónicas.
\end{abstract}

Palabras Clave: Promoción artística; catedrales; capilla funeraria; concilio; embajadores.

Abstract: Artistic historiography has often related the $15^{\text {th }}$-century renovation in Castile to the work of certain bishops and their diplomatic missions in Central Europe or Flanders, in the same way as the arrival of the Renaissance in Castile seems inextricably linked to other diplomatic figures in Italy. This work discusses a number of bishops who visited European artistic centres as ambassadors while playing a fundamental role as artistic promoters. This reconsideration examines how travel may have contributed to their commissions and how those foreign forms of expression were reflected in their artistic promotions, especially architectural ones.

Keywords: Artistic promotion; cathedrals; funerary chapel; council; ambassadors.

\section{SUMARIO}

1. Embajadas a comienzos del siglo XV. El principio de la renovación.- 2. Basilea y las embajadas del reinado de Juan II.- 3. Los obispos-diplomáticos de Enrique IV.- 4. Los obispos embajadores en tiempos de los Reyes Católicos.- 5. Bibliografía citada. 


\section{EMBAJADAS A COMIENZOS DEL SIGLO XV. EL PRINCIPIO DE LA RENOVACIÓN}

La renovación artística castellana a comienzos del siglo XV se asocia con la llegada de artistas transpirenaicos a las grandes fábricas catedralicias. Sus orígenes flamencos o normandos y bretones y, suponemos, una contrastada experiencia previa a su llegada a Castilla, avalarían a estos maestros que muy pronto controlaron algunos talleres catedralicios de finales del gótico castellano. Su papel como introductores de novedades artísticas ha sido ya puesto de manifiesto en diversas ocasiones ${ }^{1}$, pero seguimos sin poder valorar el papel que en algunos casos jugaron en su llegada los obispos y/o cabildos de estos momentos iniciales del siglo XV, pese al avance en el estudio de esta promoción eclesiástica durante los últimos años ${ }^{2}$.

Si cruzamos la información de obispos promotores asociados a la llegada de novedades artísticas con la de prelados diplomáticos de este período ${ }^{3}$, destacan personajes como don Diego Anaya y don Sancho de Rojas, asociados con viajes a reuniones conciliares en Centroeuropa y visitas a Perpiñán, o contactos con embajadas papales llegadas a Castilla en medio del conflicto del Cisma, en un momento también vinculado con la actividad de un amplio círculo de artistas del norte en el mediodía francés ${ }^{4}$.

Si nos detenemos en la figura de don Diego de Anaya Maldonado (1357-1437) veremos que su doble condición de obispo y embajador tuvo repercusiones artísticas en sus fundaciones en Salamanca. Había sido obispo de Tuy, Orense, Salamanca y Cuenca cuando fue embajador en Francia en 1395, delegado castellano en Roma a finales del siglo XIV, presente en la preparación del Concilio de Perpiñán en 1409, en Peñíscola con el Papa Luna en 1412 y asistió al Concilio de Constanza (Alemania) en 1417 dirigiendo la delegación castellana que eligió a Martín V como papa, y en 1419 de nuevo fue embajador regio para ir a Francia hasta 1420, acabando sus días como arzobispo de Sevilla ${ }^{5}$. Estos viajes han servido para relacionar la fundación de su Colegio de San Bartolomé en Salamanca -desaparecido- con la tipología de otro famoso colegio de amplia repercusión posterior, fundación de otro ilustre obispo, el Colegio Albornoz en Bolonia, ciudad visitada por el prelado tras

\footnotetext{
${ }^{1}$ Sobre el comienzo de la renovación tardogótica: Alonso 2011; Alonso, Martínez de Aguirre 2011.

${ }^{2}$ Herráez, et al. 2018.

${ }^{3}$ González 2013a, 2013b.

${ }^{4}$ Yarza 2003, p. 314; Ibáñez 2011.

${ }^{5}$ Monsalvo 2014, p. 217. Su labor como promotor artístico en Cosmen 2019.
} 
el concilio ${ }^{6}$. Sin embargo, como ha señalado Rupérez Almajano, poco tienen que ver ambos colegios en cuanto a tipología espacial. Resulta determinante el papel de Anaya en el diseño del colegio ya que desde su biógrafo Ruiz de Vergara se dice que

tiró nuestro don Diego de Anaya (...) las primeras líneas para la fundación del Colegio, que meditaba hazer, y aquella imagen que avia concebido en la idea se manifestó en un diseño, o dibuxo que della hizo ${ }^{7}$.

El planteamiento, por tanto, siguió las directrices del fundador, antes de que este visitase el colegio boloñés y fue inaugurado al poco de su vuelta del Concilio de Constanza. Distaba del modelo de Bolonia en aspectos básicos como la ubicación de la capilla interior (en Salamanca en el primer claustro, en el lienzo de fachada y con su cabecera orientada como era habitual en Castilla, frente a la capilla en eje axial del modelo italiano), o la librería, en Salamanca originalmente en alto en su fachada principal. Así, la influencia ejercida por el colegio de Bolonia, en cuanto a estatutos y organización colegial ${ }^{8}$, no afectó a los aspectos estructurales de la fundación, ya prácticamente construida cuando el prelado vuelve de sus viajes.

La fundación de su capilla funeraria en el claustro de la catedral vieja salmantina (realizada entre 1422 y 1437) sí que puede considerarse en la línea de la renovación de la arquitectura funeraria del período al cubrirse con dos tramos de bóveda de crucería con terceletes siguiendo los modelos de capillas innovadoras como la del Contador Saldaña en el monasterio de Santa Clara de Tordesillas (Valladolid) (fig. 1)9. Esta vía de renovación del lenguaje artístico nada tenía que ver con lo italiano, sino con un gusto gótico, estética en la que también se encuentran su sepulcro (realizado hacia 1430) y varias esculturas de esta capilla puestas en relación con una escuela artística relacionada geográficamente con los viajes del prelado a Centroeuropa. Camón Aznar nos hablaba de su dependencia de modelos del gótico internacional, de sepulcros de obispos realizados prácticamente a la vez por artistas muy similares en Salzburgo, Múnich, Viena, Milán o Venecia ${ }^{10}$. En relación a esta filiación estilística estarían detalles del yacente como su representación con los ojos abiertos, vivo, quizá también en referencia a haber sido esculpido en

\footnotetext{
${ }^{6}$ Sobre el colegio italiano: Serra 2006. Sobre la influencia del italiano en el salmantino Pereda 2000, pp. 27-31.

${ }^{7}$ Rupérez 2003; 2012, pp. 167, 193; Villaseñor 2012.

${ }^{8}$ Sala 1960.

${ }^{9}$ Carrero 2004, pp. 62-67; Alonso, Martínez de Aguirre 2011; Cosmen 2019, pp. 486-507.

${ }^{10}$ Camón 1940; Cendón 2003; Cosmen 2019.
} 
vida del diplomático, como por otro lado señala su testamento ${ }^{11}$. La huella del taller escultórico que realizó este sepulcro se ha visto en esculturas salmantinas, gallegas, burgalesas o en la imagen de Santa Catalina de la Capilla del Contador Saldaña en Tordesillas y la figura de un maestro, Guillén de Roán, del que más tarde hablaremos ${ }^{12}$.

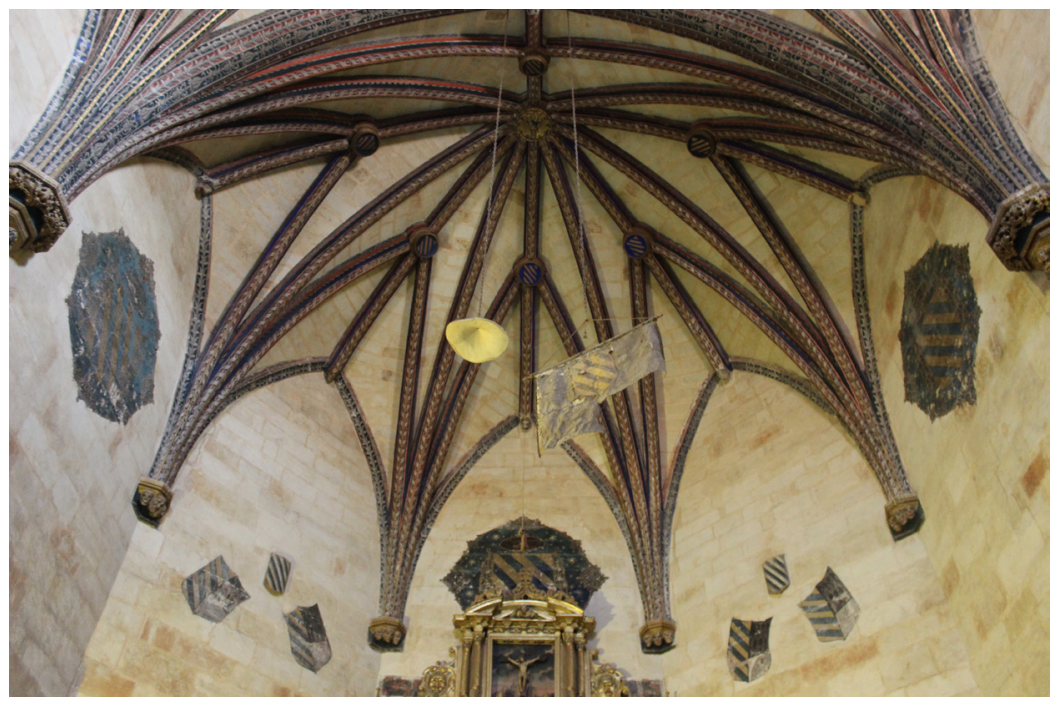

Fig. 1. Bóveda de la Capilla Anaya en el claustro de la catedral vieja de Salamanca. Foto de la autora.

Relacionado con las embajadas diplomáticas vinculadas al problema del Cisma y el Concilio de Constanza se encuentra otro prelado, don Sancho de Rojas ( $\uparrow 1422)$. Estamos ante un personaje destacado en la Castilla de la regencia de Catalina y minoría de Juan II, como miembro del Consejo de Regencia del reino, que apoyó primero al papa Benedicto XIII y llegaría a imponer en Castilla el reconocimiento de Martín V, para quien actuó como interlocutor en Castilla ${ }^{13}$.

Pese a que no existe constatación de ningún viaje suyo más allá de los Pirineos, parece que relacionado con este obispo y con sus contactos con delegados diplomáticos llegados a Castilla, se encontraría una obra donada a la capilla de Santa María de San Benito de Valladolid, hoy en el Museo Nacional de Escultura, un posible regalo entre embajadores. Se trata de la

\footnotetext{
${ }^{11}$ Lahoz 2015, p. 292.

${ }^{12}$ Cosmen 2019.

${ }^{13}$ Frenken 2009.
} 
Piedad de piedra policromada que responde a un modelo centroeuropeo, el de Bella Piedad, una novedad entonces en Castilla, vinculada a otros ejemplos conservados y todos relacionados con el regalo o la importación de este tipo de obras de manos de prelados del entorno cortesano (fig. 2) ${ }^{14}$.

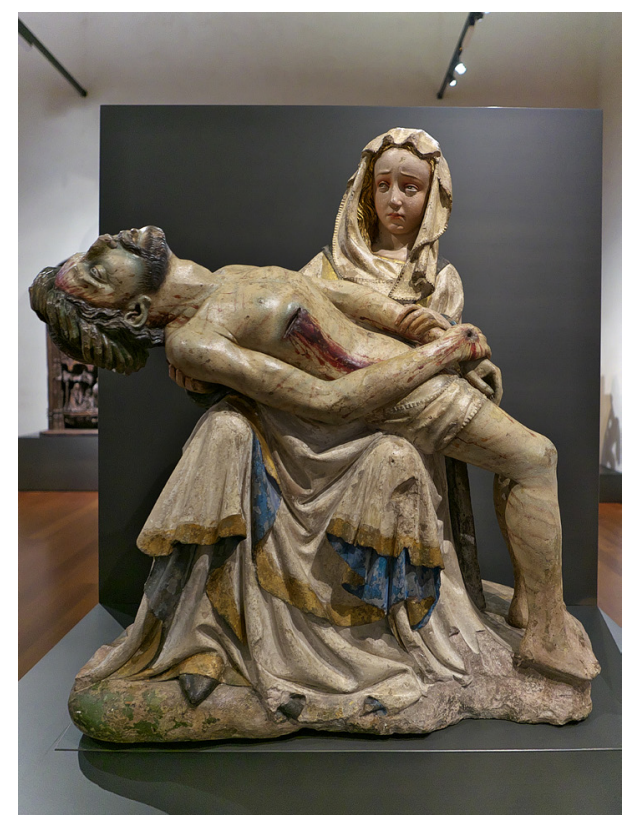

Fig. 2. Piedad de Sancho de Rojas. Museo Nacional de Escultura, Valladolid. Foto licencia Wikimedia Commons.

Don Sancho también está asociado con otras obras que supusieron un revulsivo en el contexto artístico castellano del período; estas novedades hasta donde sabemos no proceden de contactos con embajadas o viajes, pero reflejan el extraordinario interés demostrado por el prelado en relación a los nuevos lenguajes que circulaban por Europa. En este sentido supuso una novedad el retablo que don Sancho encargara para la iglesia del monasterio de San Benito, hoy en el Museo Nacional del Prado. Sobre las fechas del encargo se barajan los años 1415-1416, tras su nombramiento como arzobispo, a Juan Rodríguez de Toledo, un maestro del taller toledano heredero de la decoración de la capilla de San Blas por Starnina. En este caso, más allá de la iconografía del retablo, nos interesa subrayar que la filiación estilística del

\footnotetext{
${ }^{14}$ Herráez 2011, pp. 9-10. También Herráez 2018; Olivares 2013b, pp. 69-80; 2013 a.
} 
mismo se inclina a lo italiano, algo excepcional en la promoción del arzobispo, más inclinado al gusto gótico ${ }^{15}$.

$\mathrm{Su}$ figura como promotor se asocia a un repertorio formal y un conjunto de obras que marcan el comienzo del cambio en el tardogótico castellano y toma un impulso decisivo si analizamos su promoción artística en la catedral de Palencia, puesto que se le asocia con un grupo de artistas traspirenaicos que habían llegado a Castilla en fechas tempranas del siglo XV y que figuran primero en Aragón y más tarde en Palencia.

Por una carta del cabildo palentino anterior a octubre de 1422 (muerte del prelado) sabemos que las sillas del coro de esta iglesia que vuestra señoría mandó hacer están en buen estado y serán acabadas en breve; por dicho documento sabemos también que el obispo había reservado la cantidad de 2.000 florines para el encargo y que había mandado dar al artista 1.000 maravedíes. Este era un "maestro Centellas" que trabajaba junto a un Juan de "Lilia" y que hemos relacionado con Johannes de Liho, de Bruxellis, un maestro vinculado al círculo de artistas como Isambart o Jalopa, que se encargarían de renovar el panorama arquitectónico castellano tras su formación en tierras francesas y unos primeros trabajos en la Corona de Aragón ${ }^{16}$. Esta relación con Liho no parece descabellada si tenemos además en cuenta la otra fundación de don Sancho en Palencia, la antigua capilla mayor de la catedral. Esta obra se relaciona con la presencia de Isambart en la ciudad; se trata de la remodelación de la capilla del obispo tras la muerte de este con una nueva falsa bóveda a modo de sotechado, cortando la altura original de la capilla y creando un espacio más íntimo, reducido y fantástico, al modo de lo que había hecho Isambart en la Capilla de los Corporales de Daroca (Zaragoza) ${ }^{17}$. Así, si en la sillería tardogótica observamos la novedad del leguaje de tracerías flamígeras en madera, con vesica piscis en espiral, en la capilla podemos contemplar estas mismas decoraciones en piedra, como evidencia de la llegada de nuevas geometrías de diseño de manos de artistas extranjeros (fig. 3).

$\mathrm{Su}$ otra fundación tuvo la sede primada de Toledo como escenario; se trata de la Capilla de San Pedro que fue terminada después de la muerte del prelado $^{18}$, con novedades como su bóveda de terceletes o la tracería flamígera del ventanal cegado en el muro del Evangelio, obras a cargo de Alvar Martínez y de nuevo vinculadas a ese repertorio decorativo renovador con el que asociamos el papel promotor del obispo.

${ }^{15}$ Yarza 2003, pp. 258-260.

${ }^{16}$ Alonso 2015, p. 236. Sobre Liho, Ibáñez 2011.

${ }^{17}$ Alonso, Martínez de Aguirre 2011, p. 131; Herráez 2018.

${ }^{18}$ San Román 1928, p. 227; Azcárate 1958, p. 11; Alonso, Martínez de Aguirre 2011; Herráez 2013, p. 83. 


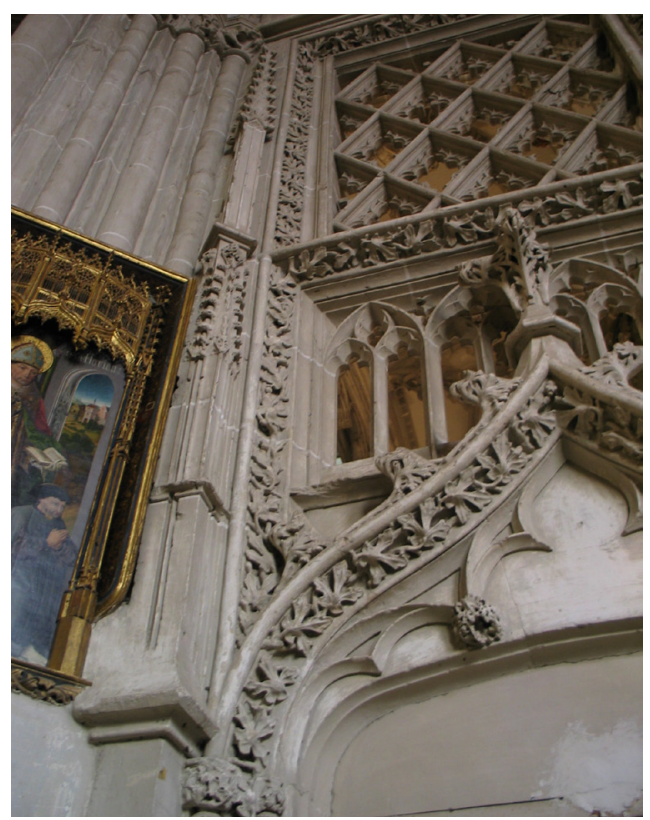

Fig. 3. Detalle arquitectónico del exterior de la capilla de Sancho de Rojas en la Catedral de Palencia. Foto de la autora.

Quien sí estuvo también en la reunión de Constanza fue el obispo de Badajoz don Juan Rodríguez de Villalón (†1424), que más tarde sería obispo de León (1419-1424). Su papel en la fábrica legionense ha sido resaltado por aumentar las rentas de la mesa capitular y destinar parte de los nuevos ingresos a la fábrica, favorecida también por la donación de parte de sus bienes. Su escudo se puede ver en las vidrieras, realizadas por artistas de procedencia francesa como Juan de Arquer, a quien se paga en 1424 y $1425^{19}$. Puede que ya para esas fechas estuviese en León otro maestro francés, esta vez encargado de su fábrica. Se trata de Guillén de Roán, que moría en 1431 y cuya lápida funeraria en el exterior de la Capilla Saldaña en Tordesillas -aún visible en el siglo XIX- decía: Aqui yace maestre Guillén de Ridan maestro de la yglesia de León et aparejador de esta capilla, e finó a VII días de deciembre año de mil et CCCC et XXX et un años. Según ello, Roán sería aparejador en una obra asociada a Isambart; de nuevo, el mismo círculo de maestros.

${ }^{19}$ Merino 1974, pp. 28, 34-35; Valdés 2004, pp. 373-374. 


\section{BASILEA Y LAS EMBAJADAS DEL REINADO DE JUAN II}

La siguiente generación de prelados diplomáticos también fue protagonista de la fundación de importantes capillas funerarias asociadas con arquitectos extranjeros, e incluso en algún ejemplo veremos la relación directa entre el viaje y la llegada de éstos. En todo caso, puede observarse en sus actitudes artísticas un compromiso con la promoción de obras vinculadas a su memoria. Políticamente nos situamos en el reinado de Juan II, tras el periodo de regencia por su minoría de edad, un reinado donde se intensifican los contactos internacionales a través de personajes relacionados con la cancillería regia y la alta prelatura eclesiástica ${ }^{20}$.

Un ejemplo de ello es don Gutierre Álvarez de Toledo (†1446), que en 1420 era canciller embajador de Juan II y del infante Enrique en Roma, donde habiendo sido revocados sus poderes, permaneció hasta 1423, en que se le concedió el obispado de Palencia (hasta 1439). Este poderoso prelado será arzobispo de Sevilla (1439-1442) y primado de Toledo (1442-1446) ${ }^{21}$. Recibió la villa de Alba de Tormes en 1429, fecha a partir de la cual se ha constatado la importancia de su labor arquitectónica como la reforma del castillo, la transformación del convento de premostratenses en fundación jerónima o la fundación de un hospita ${ }^{22}$. Las fechas nos indican que estas obras fueron en su mayoría llevadas a cabo por sus herederos. Sin embargo, recordemos que fue arzobispo de Toledo durante cuatro años, coincidiendo con la llegada, procedente de Bruselas, hacia 1443 de Hanequin Coeman (m. 1471-1472) que será nombrado maestro mayor de la catedral poco antes de 1448, siendo ya arzobispo Alfonso Carrillo de Acuña. Hasta donde sabemos hoy, no puede establecerse una relación directa entre el arzobispo y el artista flamenco, que puede que acabase implicado en las obras en Alba de Tormes, pero indica una inclinación del obispo hacia lo tardogótico frente a las novedades italianas, que había conocido en vivo, una inclinación aún más clara en otros personajes del período.

También en relación con la actividad diplomática castellana con el Papado, tuvo lugar la embajada al Concilio de Pavía-Siena en 1423 y 1424. La nómina de los castellanos incluía personajes como el otro don Sancho de Rojas -el obispo de Astorga-, pero también a don Juan Martínez de Contreras, Alfonso Carrillo o Juan de Cervantes, entonces arcediano de Sevilla ${ }^{23}$. La tra-

\footnotetext{
${ }^{20}$ Gómez 1968; Beceiro 1997; Cañas 2010.

${ }^{21}$ Cañas 2010, p. 711. Sobre el personaje: Rivera 1969, pp. 117-118; Nieto 2006.

${ }^{22}$ Parece que no llegó a hacer gran cosa el arzobispo en el monasterio: Ruiz 1997, pp. $371-$ 377. También Poza 1999; González 2013, p. 459.

${ }^{23}$ Villarroel 2007.
} 
yectoria diplomática de este último era ya para entonces extensa. El más tarde cardenal Cervantes ( $\uparrow 1453$ ), había sido nombrado en 1415 arcediano de Calatrava y dos años más tarde actuaba como procurador de Catalina de Lancaster en Peñíscola, tras ser depuesto Benedicto XIII por el Concilio de Constanza y sería jefe de la delegación española en el Concilio de Pavía-Siena, donde intervino en 1424. Tras vivir en Roma, fue nombrado cardenal en 1426 por Martín V, asistió al Concilio de Basilea como jefe de la delegación española, volvió a Castilla en 1440 por encargo del papa Eugenio IV para actuar de mediador en los bandos que se disputaban el poder. Como tal, en Valladolid en 1440 casaba al futuro Enrique IV con Blanca de Navarra; fue obispo de Ávila, Segovia y en 1446 de la diócesis de Ostia, acabando como administrador apostólico de la archidiócesis de Sevilla, ciudad en la que se estableció definitivamente a partir del verano de $1446^{24}$.

Traemos a estas páginas la figura de Cervantes por estar vinculado historiográficamente con la introducción de novedades artísticas en Sevilla, entre las que destaca la llegada a la fábrica hispalense de Lorenzo Mercadante de Bretaña. Este escultor el 16 de enero de 1454 recibía de los contadores de la catedral 400 maravedíes a cuenta de las obras que estaba realizando y el 23 de marzo otros 600 para la costa porque vino por su llamada desde Françia por una carta suya para que labrase en la yglesia ${ }^{25}$. Debe precisarse que esto ocurría ya muerto el cardenal, que había dejado previsto en su testamento de 1453 ser enterrado en su capilla de San Hermenegildo en la catedral que ya estaba construida, ordenando a sus albaceas y testamentarios nos fagan fazer las obsequias e enterramiento según vieren que conuiene, entre ellos hacer un retablo y una sepultura. Dada la rapidez de la llegada de Mercadante a Sevilla, parece clara la rapidez también en la actuación del secretario del prelado como encargado del legado. Si a estas fechas unimos la posibilidad del cobro por parte de Mercadante durante 1453 de un importe relacionado con el encargo como señala Laguna Paul, parece corroborarse la posibilidad de contactos previos entre el promotor y el artista para la realización en alabastro de su bulto funerario (fig. 4) y de la imagen devocional de la Virgen del Madroño ${ }^{26}$. Así, podría justificarse la elección del artista por su relación con la estética realista de carácter borgoñón, más en la línea de lo que había conocido en sus viajes por el Imperio, un "gusto" no italiano que ya hemos visto presente en otros prelados anteriores en relación con la talla devocional y la imagen funeraria.

\footnotetext{
${ }^{24}$ Jiménez 2006, p. 55; Laguna 2007, pp. 8-9.

${ }^{25}$ Laguna 2017, 2018.

${ }^{26}$ Laguna 2017, p. 21.
} 


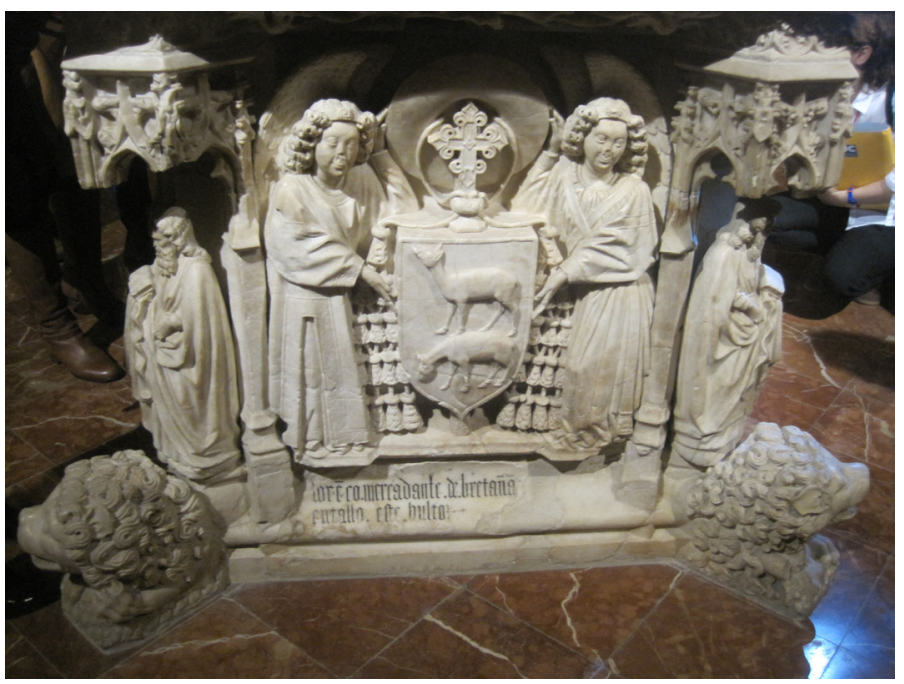

Fig. 4. Detalle del sepulcro del cardenal Cervantes

en la capilla de San Hermenegildo de la catedral de Sevilla. Foto de la autora.

También asistió al Concilio de Basilea don Alonso de Cartagena $(\dagger 1456)^{27}$. Es precisamente este viaje, uno de los muchos que realizó, el que ha sido puesto en relación con la llegada a Castilla de un arquitecto extranjero, el alemán Juan de Colonia (h. 1420-†1481). Fue Antonio Ponz el que en su Viaje publicado en 1772 recogía el texto que acompañaba al retrato del obispo en la capilla de Santa Catalina de la catedral burgalesa, un texto que parece proceder del siglo XVI, pero rehecho en el XVIII en el que se dice que

El señor D. Alonso asistió al Concilio de Basilea donde defendió, se debía al Rey de Castilla preeminencia, respecto al rey de Inglaterra (...) Traxo consigo maestros que acabaron las pirámides de esta iglesia. Fundó la Capilla de la Visitación ${ }^{28}$.

Desde este texto se ha mantenido que la llegada de Colonia estuvo asociada a la estancia centroeuropea del obispo ${ }^{29}$. Para unos el arquitecto había sido el maestro de la cartuja de Champmol, mientras que para otros tendría un origen alsaciano (asociado a obras como la aguja de la catedral de Estrasburgo en la que trabajó un maestro homónimo que pudiera haber sido un familiar suyo), o colonés, o podía que utilizase el toponímico como "sello de excelencia", o que

\footnotetext{
${ }^{27}$ Fernández 1998, 2002; Cañas 2012, p. 255.

${ }^{28}$ Payo, Martín 2018, p. 138.

${ }^{29}$ Lampérez 1903-1904.
} 
procediese de trabajar en las agujas de la catedral de Colonia ${ }^{30}$. Sin embargo, aún no se ha podido establecer la relación directa entre ambos personajes anterior a la presencia de obispo y del arquitecto en Burgos en 1442, cuando se inicia la obra de las grandes agujas, en cuyo diseño sin duda jugaron un destacado papel las flechas que el obispo vio en su viaje como las de Friburgo, Estrasburgo o la propia catedral de Basilea (fig. 5). En este sentido, sí aparecen claramente asociados viaje y obra, viaje y cambio, pues más allá de la posible relación directa con la contratación de Juan de Colonia, sí resulta claro que los elementos arquitectónicos que dispuso a su vuelta en la catedral tienen una clara inspiración centroeuropea, vinculada a un deseo de modernización o renovación de la fábrica gótica por un prelado además deseoso de dejar constancia de su memoria a través de otras fundaciones más personales como su capilla funeraria de la Visitación. Esta idea de memoria vinculada a la promoción artística tiene además en don Alonso de Cartagena un componente fundamental, pues a él se debe la reformulación filosófica de virtudes nobles como la magnificencia, vinculada al gasto suntuario, en obras como Memoriale Virtutum. Con el análisis ético realizado por Cartagena toma carta de naturaleza la plasmación de la nobleza en la promoción artística que vemos florecer a finales del siglo $\mathrm{XV}^{31}$.

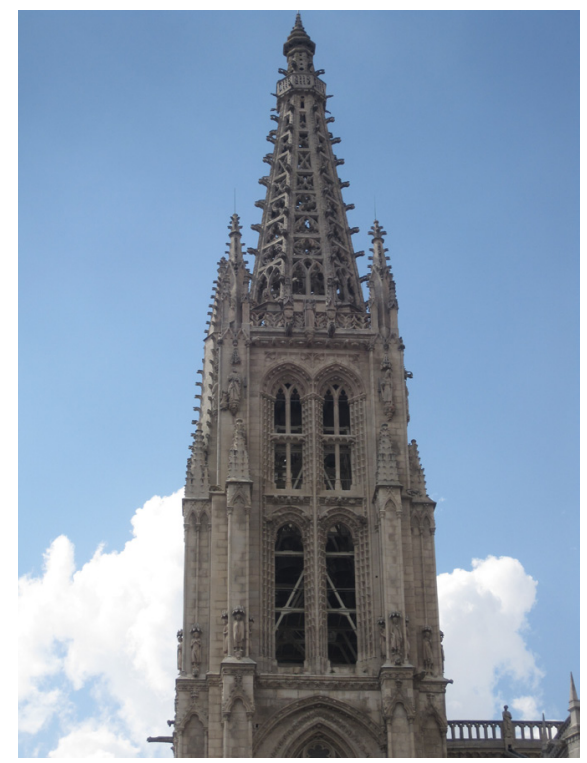

Fig. 5. Aguja de remate de la torre sur de la catedral de Burgos. Foto de la autora.

${ }^{30}$ Diferentes interpretaciones en: Tarín 1896; García 2007, 2010; Menéndez 2008, 2016, 2018.

${ }^{31}$ Alonso 2012. 
Cartagena es también fundamental en un tercer aspecto: la reivindicación del goticismo; emplea el origen godo como el plano del que deriva el honor y excelencia de la monarquía castellana en su famoso discurso ante la asamblea de Basilea. Este pasado godo, la tradición gótica, ha sido puesto en relación con la importancia que adquiere en Castilla la renovación artística gótica del siglo $\mathrm{XV}$, frente a otras opciones contemporáneas como la tradición clásica, italiana ${ }^{32}$. Quizá, en relación a ello, haya también que interpretar las obras góticas, tardogóticas, que encarga a su vuelta. Destacamos el conjunto de la capilla de la Visitación, como espacio funerario presidido por retablo y bulto funerario central, en todo ello implicado Juan de Colonia, cuya lápida funeraria significativamente se sitúa a la entrada de esta capilla ${ }^{33}$.

Además de Cervantes y Cartagena, la legación castellana en Basilea en 1434 contó con la presencia de don Álvaro de Isorna, obispo de Cuenca, o Gonzalo de Santa María, hermano de Alonso, Rodrigo Sánchez de Arévalo, discípulo de Cartagena, Alfonso Carrillo, entonces protonotario apostólico, y Juan de Torquemada.

Entre ellos desde la perspectiva de la promoción artística destaca la figura del teólogo dominico fray Juan de Torquemada ( $† 1468)$, que había asistido con su superior al Concilio de Constanza, pasando después a estudiar en París. Prior de San Pablo de Valladolid, acudiría también a Basilea, y tendría una importante actividad diplomática como miembro de la curia pontificia hasta su muerte, en lugares como Ferrara, Florencia, Francia (recibe el capelo en Bourges en 1439). Fue obispo de Cádiz (1440-1442) y de Orense (1443-1447), fundador del convento de la Minerva en Roma y responsable de la reedificación del convento de San Pablo en Valladolid, fundación que dotó con numerosos libros remitidos desde Italia y favoreció con más de un millón de maravedíes. Con este dinero se sufragó la reconstrucción del templo -sus naves, capilla mayor y capilla del Crucifijo- entre 1445 y $1468^{34}$, obra luego encubierta por el edificio de finales del siglo XV y su famosa fachada, ya a cargo de fray Alonso de Burgos, por lo que resulta imposible relacionar su promoción con ningún artista o filiación formal concreta.

\footnotetext{
${ }^{32}$ Sobre el goticismo en Cartagena: Fernández 1998. El peso de la tradición gótica en Gómez 1998, pp. 192-195.

${ }^{33}$ Sobre estas obras en la catedral, un último repaso en Payo, Martín 2018.

${ }^{34}$ Agapito 1911.
} 


\section{LOS OBISPOS-DIPLOMÁTICOS DE ENRIQUE IV}

Las relaciones de Castilla con el Papado fueron durante este período constantes, teniendo prácticamente un carácter ininterrumpido con una representación continuada durante los veinte años del reinado de Enrique IV ${ }^{35}$. En este largo período se usó de dos figuras, la del embajador especial, encargado de asuntos concretos, y la de procurador ante la Curia. Los más destacados procuradores en Roma fueron desde 1456 a 1460 los obispos Rodrigo Sánchez de Arévalo y fray Alonso de Palenzuela. Esta legación castellana estuvo apoyada por los cardenales destacados en Roma: Juan de Mella, Juan de Carvajal (muerto en Roma en 1469) y el ya anciano Juan de Torquemada.

Las figuras de Arévalo y Palenzuela nos sirven para explicar la destacada labor que realizaron muchos prelados en la reactivación de las obras de sus respectivas sedes catedralicias. En ocasiones no encontramos ejemplos directos de promoción, pero su papel se vuelve determinante en relación a la consecución de beneficios económicos y donaciones que permitieran concluir las fábricas iniciadas tiempo atrás. Esto ocurre de forma muy significativa con estos dos prelados. Ambos presentan además características en cierto modo similares. Ambos, discípulo y maestro, fueron embajadores reales en diversas ocasiones y tuvieron una importante carrera en Roma que les proporcionó contactos con humanistas y la cercanía del Papa. Para la catedral de Oviedo, Rodrigo Sánchez de Arévalo (1404-1470) fue un obispo irresidente. Sin embargo, su presencia en Roma junto a Pío II puede considerarse beneficiosa ya que el cabildo acudió a él en diversas circunstancias para conseguir su intercesión y beneficios, gracias a los cuales se reactivaron las obras con el maestro Juan de Cándamo, procedente de León ${ }^{36}$. Fue también obispo de Zamora, Calahorra y Palencia, sedes que no visitó, y tuvo una notable producción filosófica y literaria. Su actividad diplomática había comenzado acompañando a Alfonso de Cartagena a Basilea, no sólo se centró en Roma (llegó a ser alcaide de Sant'Angelo), sino que visitó Borgoña, Alemania y parte de Italia (Siena, Mantua, Viterbo) ${ }^{37}$.

Por su parte, fray Alonso de Palenzuela, franciscano, fue embajador en 1467 ante el rey de Inglaterra Eduardo IV, firmaba en el palacio de Westminster el tratado de paz y era ricamente obsequiado. Y como embajador volvería a la Curia romana en 1474. Para entonces posiblemente ya había fundado con su hermano García Alonso de Herrera la capilla funeraria familiar

\footnotetext{
${ }^{35}$ Nieto 1996.

${ }^{36}$ Caso 1981, pp. 216-223.

${ }^{37}$ La extensa bibliografía sobre este destacado intelectual en Arquero 2019.
} 
en la cabecera del monasterio franciscano de Palenzuela (Palencia) ${ }^{38}$, pero se enterró en el antiguo coro de la catedral de Oviedo, sin monumentalizar su sepultura, bajo el crucero que ayudó a concluir ${ }^{39}$. Sus armas con la fecha de 1475 figuran en el brazo meridional del transepto y en una de las capillas de este lado, la de San Antonio de Padua o de Villaviciosa, obras relacionadas con el maestro Juan de Cándamo. También se le relaciona con la finalización de la obra de la parroquial de San Juan de Palenzuela, templo al que donaría una cruz

toda de oro con dos ramos que en el uno esta la ymaxen de Nuestra Señora y en el otro de San Juan y la dicha cruz es la que dio el obispo don Alonso de Herrera a la dicha yglessia de San Juan y a el se la dio el rey de Ynglaterra como esto es muy público y notorio ${ }^{40}$.

Otra cruz también del siglo XV y también llamada "del obispo", se conserva en la actualidad en la iglesia y parece proceder del convento por tener un programa iconográfico relacionado con San Francisco, lo que la relacionaría con la promoción de don Alonso que la adquiriría en Burgos ${ }^{41}$.

\section{LOS OBISPOS EMBAJADORES EN TIEMPOS DE LOS REYES CATÓLICOS}

Durante el reinado de los Reyes Católicos la diplomacia se intensifica como herramienta fundamental del ejercicio del poder regio en el exterior; observaremos un aumento de las embajadas diplomáticas y de los personajes involucrados en ellas con nuevos perfiles ${ }^{42}$. Destaca la labor llevada a cabo por embajadores laicos como el Conde de Tendilla, Lorenzo Suárez de Figueroa o Francisco de Rojas, mientras que también seguirán siendo eclesiásticos los encargados de diversas tareas diplomáticas tanto en Roma como en otros destinos. Destacan las figuras de los obispos Juan Ruiz de Medina ( $c a$. 1440-1507), Bernardino López de Carvajal (1456-1523) y Juan Rodríguez de Fonseca (1451-1524). Todos ellos además ejercieron un relevante papel como promotores arquitectónicos a través del encargo directo de obras y el contacto con arquitectos.

Es Bernardino López de Carvajal -también cardenal y nuncio apos-

\footnotetext{
${ }^{38}$ Berzosa 2015; Martín, Abad 2014.

${ }^{39}$ Caso 1981, pp. 224-247; García 2004, pp. 1405-1406.

${ }^{40}$ Martín, Abad 2018, pp. 128-129.

${ }^{41}$ Ibidem.

${ }^{42}$ Ochoa 2003; Yarza 1993.
} 
tólico, sobrino del ya citado Juan de Carvajal- que llega a Roma ya en los años 80 del siglo $\mathrm{XV}$, el que presenta una más clara inclinación al lenguaje clásico, si bien es cierto que sus intervenciones de carácter artístico tuvieron casi con exclusividad Roma como marco. Participó en los grandes proyectos artísticos y culturales de la amplísima colonia española en Roma; actuó como agente artístico del cardenal Pedro González de Mendoza para quien encargó obras en la basílica de Santa Cruz en Jerusalén, para los reyes castellanos fue instrumento de su propaganda real en Roma, actuando como director en el encargo del Templete de San Pietro in Montorio o en la ampliación de la iglesia de Santiago de Los Españoles ${ }^{43}$. A diferencia de otros embajadores como don Jerónimo de Vich, impulsor del nuevo lenguaje con obras "italianas" como su palacio en Valencia al que orló con obras de pintores italianos, se ha insistido en que Carvajal estaba alejado de la realidad artística y cultural española, sobre cuyo suelo no se conoce que promocionase obras artísticas ${ }^{44}$.

Los otros dos obispos-embajadores citados presentan sin embargo perfiles muy diferentes. La actividad artística de Juan Ruiz de Medina (ca. 1440-1507) sí que tuvo repercusión en Castilla. Era natural de Medina del Campo (Valladolid) y se había doctorado en cánones en Salamanca en 1474, siendo colegial de San Bartolomé, el colegio de Anaya; su carrera universitaria le llevó a obtener la cátedra de Prima de Valladolid y allí debió entrar en contacto con la corte pues en 1476 fue nombrado Oidor de la Audiencia y se incorporó al Consejo Real. Ejerció un relevante papel en la política y la diplomacia del reino, actuando como embajador de Fernando e Isabel en Francia y en Roma. En esta última ciudad, a donde llegó incorporado al séquito del Conde de Tendilla, fue procurador permanente entre 1486 y 1499 , encargado de mediar en las disputas entre Inocencio VIII y el rey de Nápoles y de exaltar las victorias de la campaña de Granada. Su biografía no estaría completa sin citar su cargo de Inquisidor General de Castilla y presidente de la Real Audiencia y Chancillería de Valladolid desde 1501; moría en 1507 siendo enterrado en la capilla mayor de la iglesia que había mandado construir en su localidad natal.

Ruiz de Medina había tenido una gran implicación en las empresas romanas junto a Bernardino López de Carvajal, ya que junto a él desde 1488 fue responsable de la construcción del conjunto monasterial de San Pietro in Montorio en Roma, y de su perfil destaca su especial interés por los libros miniados y la compra del primer tratado de Vitrubio que llega a España. Además,

\footnotetext{
${ }^{43}$ Martín 2002, pp. 127-132; Fernández de Córdova 2005.

${ }^{44}$ Martín 2002, pp. 177-178.
} 
es determinante su papel en fundaciones como la capilla de la Generación de Cristo en la catedral de Sevilla y la capilla mayor de la Antigua de Medina, demolida en $1815^{45}$. Su papel como prelado de Astorga (1492), Badajoz (14931495), Cartagena (1495) y Segovia (1501-1507), le confirió una especial responsabilidad artística en estas sedes. En Astorga, financió la sillería de coro como indica su escudo en una de las misericordias. En Segovia, por ejemplo, bajo su prelatura se realizó la obra de la Librería catedralicia a cargo de Juan Gil de Hontañón a quien se manda a buscar en $1504^{46}$. La elección de este arquitecto, que no regresaría a la catedral segoviana hasta 1509, está sin duda vinculada a la figura del obispo pues le había encargado en torno a 1503 (tomó posesión de la sede en junio de ese año) las obras de la nueva capilla mayor de la Colegiata de San Antolín de su villa natal. Aunque la documentación no cita a Juan Gil en relación a esta obra hasta 1521 -cuando se construye su crucero y se materializa el proyecto salón-, desde los trabajos de García Chico es comúnmente aceptado que el planteamiento general del templo medinense es obra suya ${ }^{47}$. Pese a las diferentes fases y a los problemas constructivos que sufrirá la colegiata, la continuidad en el empleo del mismo tipo de soportes en toda la obra, así como la regularidad en su trazado, nos permiten sospechar la existencia de un planteamiento general del mismo desde su inicio, y este es el diseño que entendemos que se debe a Juan Gil (fig. 6).

El proyecto pretendía dotar de mayor monumentalidad al templo tras elevar su dignidad de parroquial a colegiata por bula de Sixto IV de junio de 1480 gracias a la intercesión real, y adquirir el patronato de la capilla mayor en marzo de 1503 para crear un espacio privilegiado de enterramiento digno de los personajes más destacados de la Castilla del momento. Una inscripción en el friso interior de la capilla alude a 1503 como posible fecha de fundación y sabemos que el 24 de enero de 1507 (el obispo moría tres días más tarde) ordenaba que se entregase un cuento de maravedíes a la colegiata para acabar la capilla que tenemos comenzada en la yglesia de san Antolín y el crucero de la dicha iglesia ${ }^{48}$. En el testamento también manifestaba su deseo de ser enterrado sin sepultura alta de piedra ni monumento, pero sus herederos años después (hacia 1540) encargaron su escultura orante en madera policromada para colocarla en el retablo mayor de la gran capilla ${ }^{49}$. Donó a la colegiata una cruz-relicario de orfebrería italiana que se conserva en su sacristía, la única evidencia artística de su paso por Roma.

\footnotetext{
${ }^{45}$ Fernández de Córdova 2013, 2014; Rodríguez 1903-1904; Villaseñor 2009.

${ }^{46}$ López 2006, p. 170.

${ }^{47}$ Castán 1998, p. 403.

${ }^{48}$ Zalama 1997, n. 44.

${ }^{49}$ Fernández de Córdova 2014, p. 127.
} 


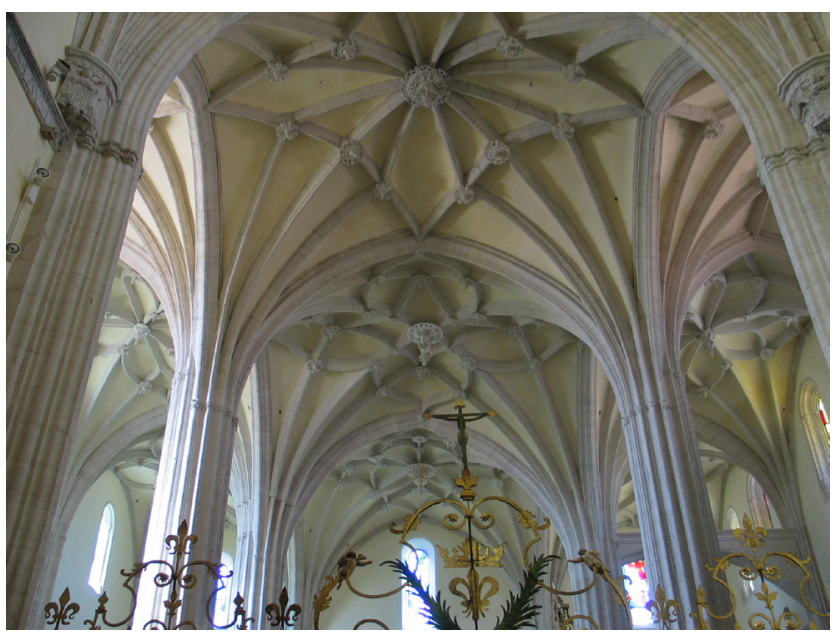

Fig. 6. Cuerpo de naves de la colegiata de San Antolín de Medina del Campo desde la cabecera, con los escudos del fundador. Foto de la autora.

La inclinación hacia el lenguaje tardogótico también se manifestó en don Juan Rodríguez de Fonseca (1451-1524). Su amplísima labor de promoción que, como veremos, abarca la iluminación de manuscritos, tapices, pinturas, pero sobre todo labor edilicia, se caracterizará por su apego a las fórmulas flamencas en relación a las artes plásticas, lo que puede ser entendido desde el conocimiento adquirido en sus viajes diplomáticos. En arquitectura se mostrará especialmente inclinado a artistas góticos con los que en algunos casos mantendrá relaciones muy estrechas, si bien observaremos a medida que avanza su vida la llegada a las obras por él promocionadas de un repertorio decorativo que abandona ya el gótico para acercarse sin duda al romano. Esto ocurre desde los últimos años de su obispado palentino y será mucho más evidente en el burgalés. Resulta significativo este hecho en un personaje que a diferencia de algunos de los que hemos recogido en estas páginas nunca visitó Italia; el análisis de su promoción artística nos sirve para introducir en este trabajo reflexiones acerca del "poder" del lenguaje tardogótico a finales de la Edad Media, en relación a su autoridad como lenguaje artístico religioso, así como para cuestionarnos sobre el papel jugado por el promotor en el diseño y planificación de las obras de arte.

Juan Rodríguez de Fonseca era oriundo de Toro (Zamora), aunque emparentado con las ramas gallega y extremeña del apellido, hijo del señor de Coca don Fernando de Fonseca y hermano del Contador Mayor de Castilla ${ }^{50}$. Llega a ser un personaje fundamental en la corte de Fernando e Isabel; en él se

${ }^{50}$ Yarza 1993, p.183; Martín 2002, pp. 132-146; Redondo 2005; Teijeira 2017. 
aunaban las letras (estudiante en Salamanca con Nebrija) y su relación con el confesor de la reina, fray Hernando de Talavera, con quien -siguiendo al cronista jerónimo Fray José de Sigüenza- le puso Isabel para que en su servicio aprendiese a ser santo $^{51}$. Su carrera religiosa se cruza con sus puestos políticos y diplomáticos. Arcediano de Olmedo, luego de Ávila y Sevilla (donde también fue deán del cabildo), Capellán Real en 1484, paje del príncipe don Juan y desde el nombramiento de Talavera como obispo de la nueva diócesis granadina, provisor de Granada. Recibirá las Sagradas Órdenes en Barcelona en 1493, coincidiendo con el retorno de Colón y con el encargo real de responsabilizarse de la gestión del segundo viaje colombino. Su carrera política se iniciaba entonces y la eclesiástica encuentra la mitra en 1495, primero como obispo de Badajoz (1495-1499), después de Córdoba (1499-1505) ${ }^{52}$, Palencia $(1505-1514)^{53}$ y finalmente de Burgos (1514-1524). Esta labor la compaginó con otros puestos en la Corte como Consejero del Consejo Real o capellán Mayor desde $1501^{54}$, Comisario General de la Cruzada, comisario papal y Presidente de la Junta de Indias, llegando a ser arzobispo de Rossano (Nápoles) desde 1511, pero nunca visitó Italia. Los encargos diplomáticos le llevaron a Francia (acompañando al embajador Rojas), Flandes (al menos en tres ocasiones: 1499,1500 y 1505) y a Inglaterra (en 1501). A esta cadena de cargos eclesiásticos y misiones políticas debemos unir la no menos importante de beneficios: la abadía de Parraces, San Isidoro de León (su patronato deja huella en el claustro) y el monasterio de San Zoilo en Carrión de los Condes (Palencia). Hábil diplomático, experto político y disfrutador de una gran privanza, ha pasado a la Historia del arte como enemigo de las estrecheces y señor del lujo, al tiempo que promotor espléndido ${ }^{55}$.

Si rastreamos en los cargos eclesiásticos de Fonseca anteriores a su llegada a la diócesis palentina, no encontraremos ningún encargo de carácter arquitectónico. Es cierto que las sedes metropolitanas de Badajoz y Córdoba conservan donaciones artísticas del obispo como recuerdo de su prelatura, pero no será hasta su nombramiento como obispo de Palencia en 1504 cuando comience a perfilarse como uno de los promotores artísticos más activos de su tiempo. La razón creemos que debe buscarse en su importante actividad diplomática como embajador en Flandes hasta 1505, lo que no le permitió realizar tareas constructivas en Badajoz o Córdoba, pero sí encargos artísticos relevantes. Así, a la catedral extremeña donó una Virgen de la Antigua que

\footnotetext{
${ }^{51}$ Teresa 1960, p. 254, citando a fray José de Sigüenza.

${ }^{52}$ Garrijo 1995.

${ }^{53}$ Sagarra 1990.

${ }^{54}$ Archivo General de Simancas, Registro General del Sello, leg. 150110, 298.

${ }^{55}$ Yarza 1993, p. 183.
} 
copiaba el original sevillano pero incluyendo un retrato del prelado como donante, así como una serie de cantorales ${ }^{56}$, como haría también para Córdoba ${ }^{57}$.

Será con la catedral palentina con la que mantenga una más dilatada y fecunda relación artística aún más allá de sus interrumpidas estancias o su marcha a Burgos en 1514, ya que siguió manteniendo con el cabildo relación epistolar sobre el estado de los trabajos que su marcha había dejado interrumpidos. Se preocupó de la conclusión del templo aún antes de entrar en la ciudad, tomando decisiones estructurales fundamentales para entender la nueva articulación del mismo. Así, el 11 de enero de 1505 había tomado posesión del obispado palentino y era recibido en la ciudad el 4 de abril de $1506^{58}$. El 15 de octubre de 1505 contrataba con el arquitecto Juan Gil de Hontañón la construcción del nuevo claustro y la sala capitular catedralicia ${ }^{59}$. Este documento se firmaba en la villa de Coca (Segovia), señorío de los Fonseca, donde se iniciaba entonces la obra de la iglesia-panteón familiar de los Fonseca. La presencia de Gil de Hontañón en Coca y las similitudes estilísticas de la iglesia con su obra sustentan la atribución de la construcción de esta interesante iglesia, uno de los pocos ejemplos castellanos con contra ábside y cabecera trebolada ${ }^{60}$. Como decimos en esa fecha el nuevo obispo de Palencia, antes de haber hecho su entrada en la diócesis, pone en manos de un arquitecto aún gótico la conclusión de la parte de las obras de la catedral que aún estaban libres, sin adjudicar y, por lo tanto, no comprometidas por encargados anteriores. Para ello elige a Juan Gil de Hontañón, que será supervisado por el arquitecto flamenco maestre Martín, miembro de la casa del obispo desde que viajase a Flandes para informar a la nueva reina Juana de la muerte de su madre ${ }^{61}$. Hasta donde hoy sabemos, esta relación tan directa entre arquitecto y promotor es un caso excepcional en este momento, pues Martín se convierte en una suerte de "supervisor arquitectónico" de cuanto encarga el obispo, siendo nombrado veedor general de la catedral desde que en 1506 figurase como "criado de su señoría". Era un clérigo de Bruselas, procedente de la diócesis de Cambrai, y en 1513 construía para el obispo su palacio en Toro (Zamora). Las obras de las naves de la catedral serán concluidas por el maestro Juan de Ruesga al haber firmado compañía con el anterior maestro de la obra ya difunto, el también cántabro Martín de Solórzano ${ }^{62}$, y estar por este contrato

${ }^{56}$ Redondo 2005.

${ }^{57}$ Yarza 1993, p. 183.

${ }^{58}$ Archivo de la Catedral de Palencia, Libro de acuerdos capitulares, 1501-1510, Posesión del obispado por don Juan Rodríguez de Fonseca, 11 enero de 1505 (ff. 105-106) y Recibimiento de la ciudad al obispo Fonseca, 4 de abril de 1506 (f. 137).

${ }^{59}$ García 1953-1954, doc. 10.

${ }^{60}$ Alonso 2005. Véase también Moreno 1990.

${ }^{61}$ Vasallo 1992.

${ }^{62}$ García 1953-1954, doc. 7. Sobre Ruesga, Alonso 2015. 
obligado a concluir las obras de su compañero. El lenguaje de este claustro y de la sala capitular resulta sobrio, comedido, sin apenas decoración más allá de las portadas de ingreso. Como sugiere Yarza, el interior de la sala capitular sólo puede entenderse en relación con la decoración de tapices, encargados por el obispo por 153971 maravedíes, hoy dispersos en diversas colecciones ${ }^{63}$.

Como hemos dicho, también el papel del obispo resulta fundamental en la reorganización del espacio interior catedralicio. Reorganizó una nueva cabecera, trasladándola más hacia el Oeste y potenciando así la sensación de la existencia de un doble transepto. No deja de ser sugerente el recuerdo de los dobles cruceros de las iglesias góticas inglesas (como Wells o Salisbury) de las que pudo tener alguna referencia en su embajada de $1501^{64}$.

Ya siendo obispo de la sede en agosto de 1505 una comisión del cabildo acordaba con Felipe de Bigarny realizar las tallas del retablo que iría en la capilla mayor pagado por el obispo Deza, ya entonces electo arzobispo sevillano. Fonseca toma ahora cartas en el asunto y reorganiza el planteamiento del retablo para readaptarlo al nuevo espacio que debía ocupar y para ello encarga un Calvario a Juan de Valmaseda y la construcción de una gran predela y nuevas calles con once tablas a Juan de Flandes por 500 ducados de oro ${ }^{65}$. El contrato con Flandes menciona de forma directa que Su Manyfica Señoría dio a fazer a Juan de Flandes, pintor, honze historias. Resulta significativo destacar que el obispo contrata al pintor real, lo que evidencia cercanía, oportunidad, capacidad económica pero también interés hacia la estética flamenca. Para entonces ya había viajado a Flandes en tres ocasiones. En una de ellas había encargado a Jan Joest de Calcar el retablo de Los Dolores de la Virgen, que luego colocaría en el trascoro catedralicio como pieza fundamental del nuevo espacio ideado al Este del templo.

En efecto, hacia los pies del templo se materializará el otro cambio substancial en la naturaleza del espacio interior del conjunto catedralicio. Fonseca encarga la ampliación de las naves a Juan de Ruesga con la adición de un nuevo tramo sobre lo ya proyectado en 1506; se inicia el nuevo coro que está asentado en 1511 y en 1513 ya se habla de la obra del trascoro cuando se acuerda que su señoria adrezase e adornase la cueva de dicha iglesia llamada soterraño y que

a espaldas del coro que se ha de pasar agora en aquella parte aderece y adorne aquella pared de las espaldas del coro y haga alli un rico altar y ponga allí un retablo que para ello digeron que habia dado todo de la manera que a su señoria mejor le paresciera y que perpetuamente digan cada sábado la misa de prima que suelen

\footnotetext{
${ }^{63}$ Yarza 1993; San Martín 1953, p. 295. Sobre los tapices Zalama, Martínez 2007.

${ }^{64}$ Yarza 1993, p. 184.

${ }^{65}$ Revilla 1950, p. 93; San Martín 1953.
} 
decir al altar mayor e asy mesmo que todos los sábados digan al dicho altar la salve cantada, y todos vengan a ella ${ }^{66}$.

El mismo contenido tiene la carta publicada por Eloísa García en 1945 y que podemos fechar en ese noviembre de 1513, antes de su marcha a Burgos pues declara que

aunque dexemos la posesión de nra santa iglesia de Palencia tenemos voluntad de acabar el trascoro que hacemos la dicha memoria que está a la entrada de la cueva del glorioso mártir santo Antolin antes de la escalera que baxa a la cueva ${ }^{67}$.

El obispo planteaba así la creación de un nuevo espacio focal en el interior catedralicio; retomaba una idea presente en otras catedrales castellanas como la de Toledo que preeminenciaba la arquitectura de los muros del coro como si de fachadas exteriores se tratasen y el trascoro como si fuese el principal, encarado hacia la entrada del templo desde los pies. Este paño occidental, considerado como "la fachada principal del nuevo templo" que define Fonseca, está estructurado como si de un retablo se tratase y en él ya observamos elementos propios de un lenguaje renacentista como los roleos que decoran las puertas de los primeros paños del trascoro, así como el empleo de arcos de medio punto, hornacinas aveneradas o la entalladura de sus puertas, las primeras manifestaciones del nuevo repertorio renacentista en Palencia (fig. 7).

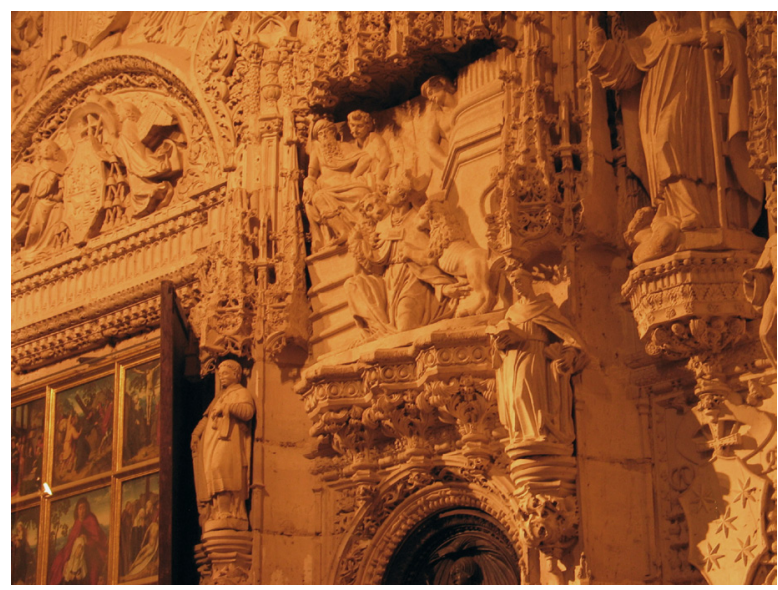

Fig. 7. Detalle de la fachada del trascoro de la catedral de Palencia. Foto de la autora.

\footnotetext{
${ }^{66}$ Archivo Catedral de Palencia, Actas capitulares de 1513, f. 115.

${ }^{67}$ García 1944-1945, p. 183.
} 
Ya hemos comentado que para esta fachada interior el prelado había encargado en Flandes a Jan Joest de Calcar el retablo de Los Dolores de la Virgen, en cuya tabla central figura un retrato del prelado como orante ${ }^{68}$. Así, sobre la cripta de San Antolín, y abierto hacia los pies del templo, se intentaba generar un nuevo punto focal en el espacio interior catedralicio, ahora vinculado a la figura de la Virgen. En este contexto cobran sentido los tapices flamencos dedicados a la Salve donados en 1527 por su hermano Antonio de Fonseca a la catedral siguiendo las instrucciones del testamento del obispo $^{69}$, evidenciando la creación de lo que Yarza dio en denominar un nuevo espacio virtual dedicado a la liturgia mariana ${ }^{70}$. Este nuevo espacio se colocó significativamente sobre la cripta de San Antolín, espacio de alto poder simbólico dentro del conjunto catedralicio, al que se abrió paso gracias a una escalera decorada con relieves con imágenes del martirio de San Antolín y la cacería del jabalí por el rey don Sancho el mayor de Navarra, acontecimiento vinculado al descubrimiento de la cripta con los restos del santo patrón. En uno de los paneles interiores de la escalera leemos la fecha de 5 de marzo de $1516(M A / R / Z O / V 16)$ para la que se ha sugerido la labor de entalladores burgaleses ${ }^{71}$.

La Bella Desconocida conserva otras obras también vinculadas a Fonseca y que enlazan con esta nueva estética al romano. En la portada de San Juan o de los Reyes en el crucero norte de la catedral, se observan diseños ornamentales "a lo romano" similares a los de la escalera de acceso a la cripta. La portada fue iniciada a finales del siglo XV como indican sus arquivoltas apuntadas, pero fue terminada durante la maestría de Ruesga con decoración de su tímpano con diseños "a lo romano" que José Camón Aznar relacionó con la decoración de la fachada de la Universidad de Salamanca $^{72}$. Por la labor de los sillares combinando decoración vegetal gótica con elementos ornamentales a la italiana, entendemos que existe una unidad de diseño. Los modelos que inspiraron las composiciones de los relieves del tímpano pueden encontrarse en el Sueño de Poliphilo de Francesco Colonna (Venecia, imprenta de Aldo Manuzio, 1499) como demuestra la composición del relieve con dos niños desnudos colgando de un candelabro vegetal, mo-

${ }^{68}$ En sus puertas se puede leer "Anno de MCU el reverendo e magnifico Señor don Juan de Fonseca por la gracia de Dios obispo de Palencia conde de Pernía mandó hazer esta imagen de nostra señora de la Compassión estando en Flandes por en-baxador con el Señor Rey don Felipe de Castilla e con la Reyna doña Juana nuestros señores": cf. Reyes y Mecenas, pp. 326-327. También Granados 2008.

${ }^{69}$ García 1948.

${ }^{70}$ Yarza 1989.

${ }^{71}$ Redondo 2005, p. 192.

${ }^{72}$ Camón 1945, p. 311. 
tivo extendido a otras producciones contemporáneas a la palentina, como los relieves de la escalera de la universidad de Salamanca ${ }^{73}$. El repertorio de fuentes utilizadas también incluía a Giovanni Antonio da Brescia, como se refleja en la gran ménsula sobre la que descansa el "sobrecoro" (fig. 8).

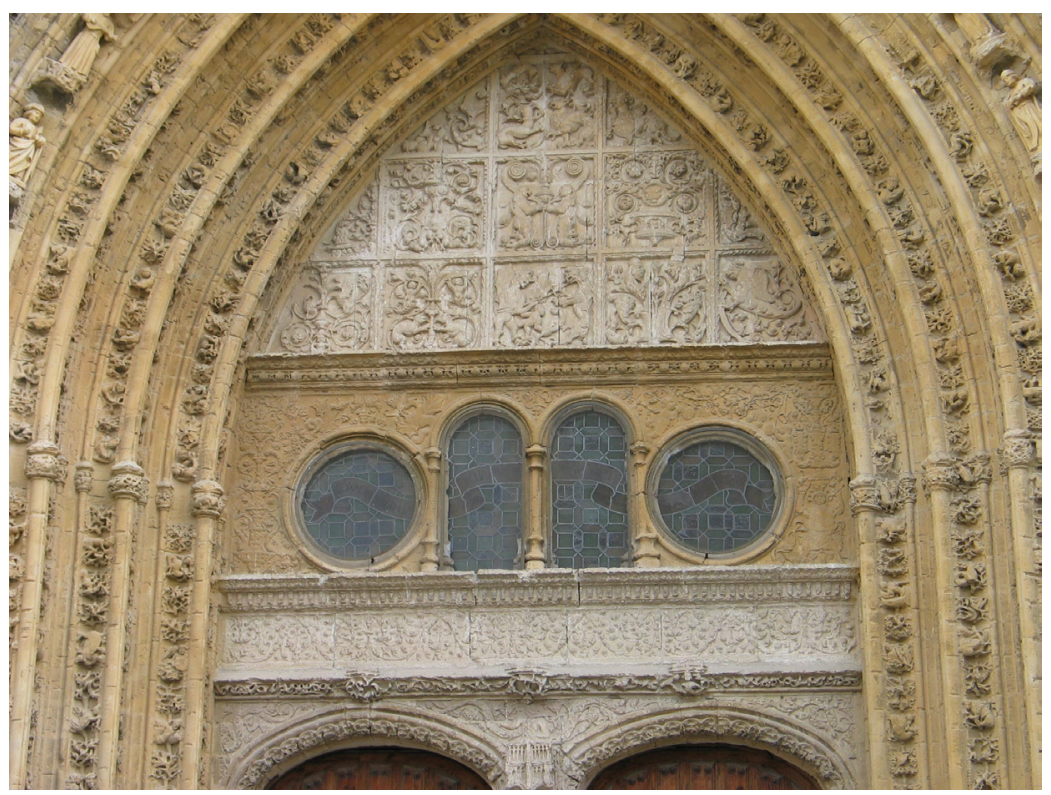

Fig. 8. Detalle de la Portada de los Reyes de la Catedral de Palencia. Foto de la autora.

Estas últimas obras palentinas nos llevan a Burgos, pues fueron ya realizadas siendo Fonseca obispo burgalés y comparten con las obras relacionadas con el obispo en Burgos la inclinación al lenguaje romano. Quizá haya que buscar a los maestros de la portada de los Reyes o de la escalera de la cripta en el taller burgalés, pues allí encargó el obispo la famosa Escalera Dorada. A diferencia de Palencia, su relación con el cabildo burgalés fue complicada; el propio Fonseca escribe sobre los monipodios, conventículos y conspiraciones de algunos miembros del cabildo ya antes de su toma de posesión de la mitra burgalesa ${ }^{74}$. Uno de los motivos de diferencias nos afecta pues se trata de la intención del obispo de construir un puente o levadizo entre sus palacios y la catedral, razón de discordia que acabaría decantándose a favor del cabildo. El cabildo también se opuso al cierre en 1516 de la Puerta de la Coronería

\footnotetext{
${ }^{73}$ Pereda 2000.

${ }^{74}$ Martín 2002, p. 134.
} 
que comunicaba el transepto de la catedral con la parte alta de la ciudad ${ }^{75}, \mathrm{y}$ para aliviar esta comunicación ahora interrumpida ese mismo año Fonseca encargaba a Francisco de Colonia -nieto del Juan llegado de Alemania-, la creación de la Puerta de la Pellejería que venía a dar solución al problema de la comunicación del transepto catedralicio con la ciudad alta. Las estampas -como había ocurrido en Palencia-, parecen ser la inspiración de esta nueva puerta, pues Colonia tampoco había estado en Italia. Así, el resultado fue un híbrido entre los repertorios decorativos gótico y romano al combinar escamas y macollas con pilastras a candelieri.

Fonseca volvería al tema del transepto norte catedralicio tres años más tarde al presentar una solución ante el cabildo. El 4 de noviembre de 1519:

Este día Su Señoria propuso sobre que quería tornar á facer la escalera en la puerta alta de la correría donde solía, la cual el había mandado quitar et que agora la quería facer conforme á una traza que mostró en el dicho Cabildo Diego Sylue imaginario, en presencia de Su Señoria é de los dichos señores ${ }^{76}$.

El protagonismo del lenguaje clásico de esta gran obra se debe a Diego de Siloé, como el dudoso conocimiento de lo clásico se debe a Colonia o a Ruesga en Palencia. Como hemos visto, el diseño fue presentado por el obispo al Cabildo, pero evidencia un conocimiento directo de lo clásico que el promotor en ningún caso tenía. Volutas, grifos, jarrones, candelabros, balaustres, putti, hablan de una experiencia artística madurada en Italia, con afinidades ya resaltadas con obras de Francesco di Giorgio Martini, los Sangallo o Bramante en el cortile del Belvedere del Vaticano, y con un repertorio decorativo también relacionado con grabados de Brescia o Nicoletto da Modena (fig. 9) ${ }^{77}$.

La promoción artística de Rodríguez de Fonseca abarca además multitud de obras, de hospitales en Toro y Burgos, donaciones de tapices, libros de canto y arte suntuario que exceden el contenido de este trabajo, como también lo excede su papel en determinadas obras reales como el proyecto de la Capilla real de Granada, al que envía en 1512 a sus arquitectos palentinos. Su criado, Maestre Martín, aún trabajaba en 1520 y pese a ello no parece tener relación con la etapa burgalesa de su patrón. ¿El cabildo burgalés fue más reacio que el palentino respecto a la imposición de maestros por parte del obispo? Así parece si tenemos en cuenta las desavenencias entre cabildo y prelado y que éste encargase a un maestro "de la casa" como Francisco de Colonia su primera promoción en Burgos. Más desconcertante es el papel jugado por Fonseca en relación al en-

\footnotetext{
${ }^{75}$ Martínez 1866, p. 125.

${ }^{76}$ Speranza 2001, p. 19.

${ }^{77}$ Además de lo ya citado, véase Sebastián 1962; Wethey 1964; Fernández 1987, pp. 283-300.
} 
cargo de la Escalera Dorada, pues el documento citado nos indica que Fonseca apoyó los diseños de un Siloé que había vuelto a trabajar en la catedral burgalesa después de su periplo napolitano, siendo también un viejo conocido del taller burgalés donde se había formado en su juventud y que había abandonado con problemas. Así, la obra más italiana de cuantas hemos visto en estas páginas se debió a la promoción de un prelado que no había estado en Italia.

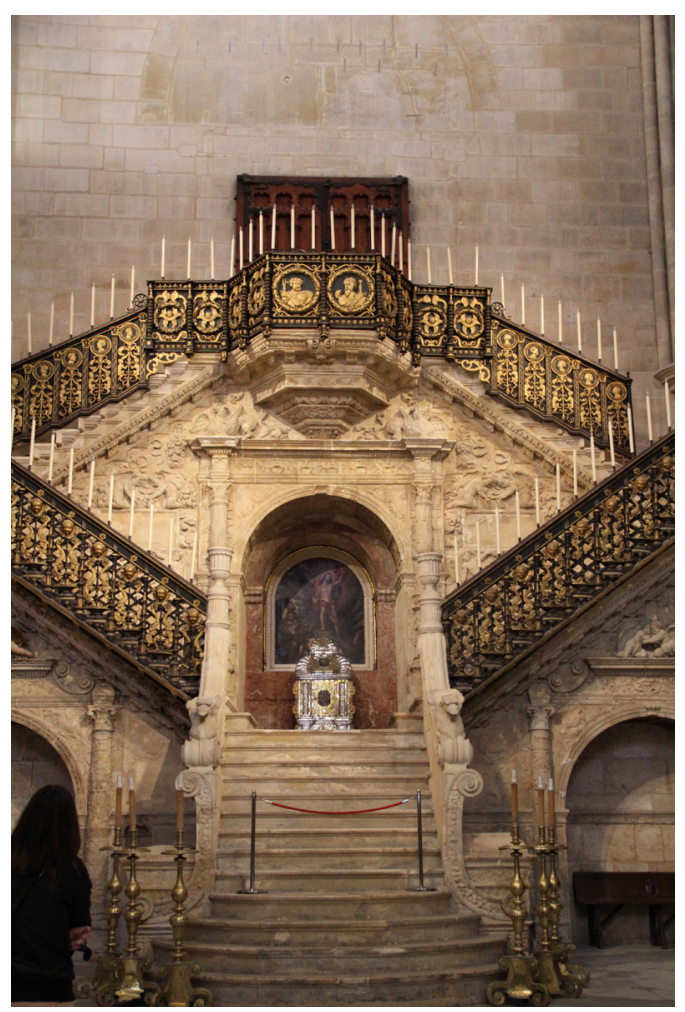

Fig. 9. Escalera Dorada de la catedral de Burgos. Foto de la autora.

Yarza escribía que los principales impulsores del cambio artístico del siglo XV -al menos en escultura y arquitectura-, fueron los obispos viajeros ${ }^{78}$. Después de este repaso por las trayectorias más representativas de los obispos diplomáticos asociadas al arte castellano del siglo XV conviene precisar que esta renovación artística fue mayoritariamente tardogótica, de la mano de artistas del norte, en orfebrería, pintura, escultura o arquitectura. El lenguaje

\footnotetext{
${ }^{78}$ Yarza 2003, p. 314.
} 
"a lo romano" no dejó prácticamente huella en las obras que encargaron en Castilla, y cuando sí lo hizo (casos en las sedes palentina o burgalesa) no llegó por la vía del promotor, sino del artista y ya en el siglo XVI. Estos obispos diplomáticos desarrollaron su magnificencia promoviendo obras que ensalzaran su memoria, ancladas en la auctoritas del lenguaje gótico.

\section{BiBliografía CitADA}

Agapito y Revilla, Juan (1911), Del Valladolid Monumental. La iglesia del convento de San Pablo y el Colegio de San Gregorio, Valladolid, Imprenta del Colegio Santiago.

Alonso Ruiz, Begoña (2005), Un modelo funerario del Tardogótico castellano: las capillas treboladas, "Archivo Español de Arte" 311, pp. 277-295.

Alonso Ruiz, Begoña (2011), Los tiempos y los nombres del tardogótico castellano, en La arquitectura tardogótica entre Europa y América, Madrid, Silex, pp. 43-80.

Alonso Ruiz, Begoña (2012), La nobleza en la ciudad. Arquitectura y magnificencia a finales de la Edad Media, "Studia Historica" 34, pp. 215-251.

Alonso Ruiz, Begoña (2015), El coro y el trascoro de la catedral de Palencia. Arquitectos y entalladores del Tardogótico, en Villaseñor Sebastián, Fernando; Teijeira Pablos, María Dolores; Muller, Welleda; Billiet, Frédéric (eds.), Choir stalls in architecture and architecture in choir stalls, Newcastle upon Tyne, Cambridge Scholars Publishing, pp. 234-249.

Alonso Ruiz, Begoña; Martínez de Aguirre, Javier (2011), Arquitectura en la Corona de Castilla en torno a 1412, "Artigrama" 26, pp. 103-148.

Arquero Caballero, Guillermo Fernando (2019), La bibliografía de Rodrigo Sánchez de Arévalo de acuerdo con su trayectoria vital, "Cuadernos Medievales", pp. 31-49.

Azcárate Ristori, José María (1958), La arquitectura gótica toledana del siglo $X V$, Madrid, Instituto Diego Velázquez.

Beceiro Pita, Isabel (1997), La consolidación del personal diplomático entre Castilla y Portugal (1392-1455), en La Península Ibérica en la Era de los Descubrimientos, 1391-1455, Actas de las III Jornadas Hispanos-Portuguesas de Historia Medieval, vol. II, Sevilla, Junta de Andalucía, pp. 1735-1744.

Berzosa Martínez, Cecilio Raúl (2015), Fray Alonso de Palenzuela, Obispo de Ciudad Rodrigo (1460-1479) y de Oviedo (1470-1485): religioso, escritor, pastor, reformador y diplomático, "Revista Española de Derecho Canónico" 72, pp. 367-382. 
Camón Aznar, José (1940), El escultor del arzobispo Anaya, "Revista de la Universidad de Zaragoza" 17/1, pp. 3-27.

Camón Aznar, José (1945), La arquitectura plateresca, Madrid, Instituto Diego Velázquez.

Cañas Gálvez, Francisco de Paula (2010), La diplomacia castellana durante el reinado de Juan II: la participación de los letrados de la cancillería real en las embajadas regias, "Anuario de Estudios Medievales" 2, pp. 691-722.

Cañas Gálvez, Francisco de Paula (2012), Burocracia y cancillería en la corte de Juan II de Castilla (1406-1454). Estudio institucional y prosopográfico, Salamanca, Ediciones Universidad de Salamanca.

Carrero Santamaría, Eduardo (2004), La catedral vieja de Salamanca. Vida capitular y arquitectura en la Edad Media, Murcia, Nausicaa.

Caso Fernández, Francisco (1981), La construcción de la catedral de Oviedo (1293-1587), Oviedo, Universidad de Oviedo.

Castán Lanaspa, Javier (1998), Arquitectura religiosa en Valladolid y su provincia. Siglos XIII-XVIII, Valladolid, Editora Provincial.

Cendón Fernández, Marta (2003), Aspectos iconográficos del sepulcro del arzobispo Diego de Anaya, "Boletín del Museo e Instituto Camón Aznar" 90, pp. 39-54.

Cosmen Alonso, María Concepción (2019), Memoria de Diego de Anaya y Maldonado (†1437). Ilustración, crítica y devoción, en Boto, Gerardo; Escandell, Isabel; Lozano, Esther (eds.), The Memory of the Bishop in Medieval Cathedrals. Ceremonies and Visualizations, Berna, Peter Lang, pp. 463-509.

Fernández de Córdova y Miralles, Álvaro (2005), Imagen de los Reyes Católicos en la Roma pontificia, "En la España Medieval” 28, pp. 259-354.

Fernández de Córdova y Miralles, Álvaro (2013), Ruiz de Medina, Juan, en Diccionario Biográfico Español, Madrid, Real Academia de la Historia, pp. 784-786.

Fernández de Córdova y Miralles, Álvaro (2014), Diplomáticos y letrados en Roma al servicio de los Reyes Católicos: Francesco Vitales di Noya, Juan Ruiz de Medina y Francisco de Rojas, "Dicenda. Cuadernos de Filología Hispánica" 32, pp. 113-154.

Fernández Gallardo, Luis, (1998), Alonso de Cartagena. Iglesia, política y cultura en la Castilla del siglo XV, Madrid, Universidad Complutense (tesis doctoral).

Fernández Gallardo, Luis (2002), Alonso de Cartagena (1385-1456). Una biografía política en la Castilla del siglo XV, Valladolid, Junta de Castilla y León. 
Fernández Gómez, Margarita (1987), Los grutescos en la arquitectura espanola del protorrenacimiento, Valencia, Generalitat.

Frenken, A. (2009), El trabajoso y difícil camino hacia la unión: Sancho Sánchez de Rojas, arzobispo de Toledo, y el papel clave que jugó en la extinción del gran cisma de Occidente en el reino de Castilla, "En la España Medieval", 32, pp. 51-83.

García, Eloisa (1944-45), El trascoro de la catedral de Palencia, "Boletín del Seminario de Arte y Arqueología" 11, pp. 179-184.

García, Eloisa (1948), Los tapices de Fonseca en la catedral de Palencia. II. Tapices de la Salve, "Boletín del Seminario de Arte y Arqueología" 14, pp. 189-203.

García Cuesta, Timoteo (1953-1954), La catedral de Palencia según los protocolos, "Boletín del Seminario de Arte y Arqueología" 20, pp. 91142.

García Cuetos, María Pilar (2004), "De cómo se çerró y acabó la santa yglesia de Oviedo". La Sancta Ovetensis bajo el reinado de Isabel la Católica, en Isabel la Católica y su época. Actas del congreso internacional, vol. II, Valladolid, Universidad de Valladolid, pp. 1403-1420.

García Cuetos, María Pilar (2007), Les dames de l'horizon. Les flèches ajourées comme expression du pouvoir et la recréation hispanique d'un modèle européen, "E-Spania: Revue électronique d'études hispaniques médiévales" [en línea] 3, DOI: 10.4000/e-spania.476 [consulta: 9/01/2020].

García Cuetos, María Pilar (2010), En los límites de la sombra como arquetipo historiográfico. La llegada de Juan de Colonia y su aportación a la arquitectura tardogótica en Castilla, en Alonso Ruiz, Begoña (coord.), Los últimos arquitectos del gótico, Madrid, Marta FernándezRañada, pp. 71-148.

Garrijo Pérez, Ignacio (1995), Don Juan Rodríguez de Fonseca, obispo de Córdoba. Un olvidado rastro heráldico, "Boletín de la Real Academia de Córdoba de Ciencias, Bellas Artes y Nobles Artes" 66, pp. 347-352.

Gómez Izquierdo, Alicia (1968), Cargos de la Casa y Corte de Juan II de Castilla, Valladolid, Universidad de Valladolid.

Gómez Martínez, Javier (1998), El gótico español de la Edad Moderna. Bóvedas de crucería, Valladolid, Universidad de Valladolid.

González Sánchez, Santiago (2013a), Las relaciones exteriores de Castilla a comienzos del siglo XV. La minoría de Juan II (1407-1420), Madrid, Comité Español de Ciencias Históricas.

González Sánchez, Santiago (2013b), Los obispos castellanos en los inicios del siglo XV (1407-1420), "Estudios sobre Patrimonio, Cultura y Ciencias Medievales"15, pp. 187-214. 
González Zymla, Herbert (2013), El castillo palacio de los Álvarez de Toledo en Alba de Tormes, "Anales de Historia del Arte" 23, pp. 455-468.

Granados Salinas, Rosario Inés (2008), Sorrows for a devout ambassador. A netherlandish altarpiece in sixteenth century Castile, "Potestas" 1, pp. 101-130;

Herráez Ortega, María Victoria (2011), Castilla, el concilio de Constanza y la promoción artística de don Sancho de Rojas, "Goya" 334, pp. 5-19.

Herráez Ortega, María Victoria (2013), La fundación y dotación de la Capilla de San Pedro en la Catedral de Toledo, "Laboratorio de Arte" 25, pp. 79-96.

Herráez Ortega, María Victoria (2018), The Episcopal imprint in the Cathedral of San Antolin in Palencia. The constructition of a gothic chevet (1321-1460), en Herráez Ortega, María Victoria; Cosmen Alonso, María Concepción; Teijeira Pablos, María Dolores; Moráis Morán, José Alberto (eds.), Obispos y catedrales. Arte en la Castilla bajomedieval, Berna, Peter Lang, pp. 233-240.

Herráez Ortega, María Victoria; Cosmen Alonso, María Concepción; Teijeira Pablos, María Dolores; Moráis Morán, José Alberto (eds.) (2018), Obispos y catedrales. Arte en la Castilla bajomedieval, Berna, Peter Lang.

Ibáñez Fernández, Javier (2011), Seguendo il corso del sole: Isambart, Pedro Jalopa e il rinnovamento dell'ultimo gotico nella penisola iberica durante la prima metà del XV secolo, "Lexicon" 12, pp. 27-44.

Jiménez Martínez, Alfonso (2006), Las fechas de las formas, en La catedral gótica de Sevilla. Fundación y fábrica de la obra nueva, Sevilla, Universidad de Sevilla, pp.15-113.

Laguna Paul, Teresa (2017), Un escultor para un cardenal. Lorenzo Mercadante de Bretaña y el sepulcro de Juan de Cervantes: nuevas lecturas documentales, "De Arte" 16, pp. 7-30.

Laguna Paul, Teresa (2018), Memoria funeraria y patronazgo de Juan de Cervantes en la catedral de Sevilla. Mercadante de Bretaña y las obras de la capilla de san Hermenegildo, en Herráez Ortega, María Victoria; Cosmen Alonso, María Concepción; Teijeira Pablos, María Dolores; Moráis Morán, José Alberto (eds.), Obispos y catedrales. Arte en la Castilla bajomedieval, Berna, Peter Lang, pp. 75-120.

Lahoz, Lucia (2015), Patronato, gusto y devoción del Arzobispo Anaya, en Lienzos del Recuerdo. Estudios en Homenaje a José M. ${ }^{a}$ Martínez Frías, Salamanca, Ediciones Universidad de Salamanca, pp. 291-300.

Lampérez y Romea, Vicente (1903-1904), Juan de Colonia. Estudio biográfico-crítico, "Boletín de la Sociedad Castellana de Excursiones" 19, pp. 351-356. 
López Díez, María Blanca (2006), Segovia en la época de los Trastámara. Juan Guas, maestro de obras reales, Segovia, Caja Segovia.

Martín Ansón, María Luisa; Abad Castro, Concepción (2014), Los panteones de los Herrera en Palenzuela: la capilla mayor del convento de San Francisco y la capilla de San Bartolomé en la iglesia de San Juan, Palencia, Institución Tello Téllez de Meneses.

Martín Ansón, María Luisa; Abad Castro, Concepción (2018), Fray Alonso de Palenzuela: promoción artística en su villa natal y en la catedral de Oviedo, en Franciscanos en la Edad Media: memoria, cultura y promoción artística, Alessandria, Edizioni dell'Orso, pp. 117-143.

Martín García, Juan Manuel (2002), Arte y diplomacia en el reinado de los Reyes Católicos, Madrid, Fundación Universitaria Española.

Martínez Sanz, Manuel (1866), Historia del templo catedral de Burgos, escrita con arreglo a documentos de su archivo, Burgos, Imprenta de don Anselmo Revilla.

Menéndez González, Nicolás (2008), Juan de Colonia en los inicios del tardogótico burgalés, en Actas del IV Simposio Internacional de Jóvenes Medievalistas, Murcia, Universidad de Murcia, pp. 147-148.

Menéndez González, Nicolás (2016), "Sunder von vil andern grossen berumbte maisteren": las obras de la capilla de la Visitación y la fachada de la catedral de Burgos, marco de la aparición de Juan de Colonia en la ciudad. La reestructuración del taller catedralicio (h.14441447), en 1514. Arquitectos tardogóticos en la encrucijada, Santander - Sevilla, Universidad de Sevilla, pp. 91-106.

Menéndez González, Nicolás (2018), Studien zum empirischen Konstruieren Juan de Colonia (†1476/78). Form- und Herstellungswissen im Protostadium einer Ära des Architekturtraktats, Colonia, Kölner Architekturstudien, 2 vols.

Merino Rubio, Waldo (1974), Arquitectura hispano flamenca en León, León, Institución "Fray Bernardino de Sahagún".

Monsalvo Antón, José María (2014), Diego de Anaya (1357-1437) y su tiempo. Aristócrata, obispo, diplomático y humanista, en La Universidad de Salamanca y el Pontificado en la Edad Media, Salamanca, Publicaciones de la Universidad Pontificia.

Moreno Alcalde, María (1990), Los Fonseca y la iglesia de Santa María de Coca, en "Anales de Historia del Arte" 2, pp. 57-77.

Nieto Soria, José Manuel (1996), Enrique IV de Castilla y el Pontificado (1454-1474), “En la España Medieval” 19, pp. 167-238.

Nieto Soria, José Manuel (2006), Un crimen en la corte. Caída y ascenso de Gutierre Álvarez de Toledo. Señor de Alba (1376-1446), Madrid, Sílex. 
Ochoa Brun, Miguel Ángel (2003), Historia de la Diplomacia Moderna. Los Reyes Católicos. Madrid, Ministerio de Asuntos Exteriores, $\left(1 .^{\text {a }}\right.$ edición, 1995).

Olivares, Diana (2013a), Albornoz, Tenorio y Rojas: las empresas artísticas de tres arzobispos de Toledo en la Baja Edad Media. Estado de la Cuestión, "Estudios Medievales Hispánicos" 2, pp. 129-174.

Olivares, Diana (2013b), Alonso de Burgos y la arquitectura castellana en el siglo XV. Los obispos y la promoción artística en la Baja Edad Media, Madrid, La Ergástula.

Payo Hernánz, René Jesús; Martín Martínez de Simón, Elena (2018), Alonso de Cartagena: política, religión y mecenazgo en la Castilla de mediados del siglo XV, en Herráez Ortega, María Victoria; Cosmen Alonso, María Concepción; Teijeira Pablos, María Dolores; Moráis Morán, José Alberto (eds.), Obispos y catedrales. Arte en la Castilla bajomedieval, Berna, Peter Lang, pp. 121-162.

Pereda, Felipe (2000), La arquitectura elocuente. El edificio de la Universidad de Salamanca bajo el reinado de Carlos V, Madrid, Sociedad Estatal para la conmemoración de los centenarios de Felipe II y Carlos V.

Poza Yagüe, Marta (1999), La capilla mayor del monasterio de San Leonardo de Alba de Tormes, panteón funerario de los Álvarez de Toledo. Precisiones acerca de su estructura, en La Orden de San Jerónimo y sus monasterios. Actas del Simposio. San Lorenzo de El Escorial, Escorial, Real Centro Universitario Escorial-María Cristina, pp. 338-357.

Redondo Cantera, M. ${ }^{a}$ José (2005), Juan Rodríguez de Fonseca y las artes, en Sagarra Gamazo, Adelaida (coord.), Juan Rodríguez de Fonseca: su imagen y su obra, Valladolid, Universidad de Valladolid, pp. 178-179.

Reyes y Mecenas. Los Reyes Católicos-Maximiliano I y los inicios de la casa de Austria en España. Catálogo de la Exposición (1992), Toledo, Ministerio de Cultura - Patrimonio Nacional.

Rivera Recio, Juan Francisco (1969), Los arzobispos de Toledo en la Baja Edad Media, Toledo, Diputación Provincial.

Ruiz Hernando, José Antonio (1997), Los monasterios jerónimos españoles, Segovia, Caja Segovia.

Rupérez Almajano, María Nieves (2003), El colegio mayor de San Bartolomé $o$ de Anaya, Salamanca, Universidad de Salamanca.

Rupérez Almajano, María Nieves (2012), El Colegio de San Bartolomé antes de las reformas del siglo XVIII, "Miscelánea Alfonso IX", pp. 159-210.

Sagarra Gamazo, Adelaida (1990), Don Juan Rodríguez de Fonseca, obispo de Palencia, en Actas del II Congreso de Historia de Palencia, vol. IV, Palencia, Diputación Provincial, pp. 489-500. 
Sala Balust, Luis (1960), Las primeras constituciones del Colegio de San Bartolomé de Salamanca, copia de los primeros estatutos del Colegio de San Clemente de Bolonia, "Estudios Eclesiásticos" 35, pp. 253-263. San Martín Payo, Jesús (1953), El retablo mayor de la catedral de Palencia. Nuevos datos, "Publicaciones de la Institución Tello Téllez de Meneses" 10, pp. 273-312.

San Román, Francisco de Borja (1928), La capilla de San Pedro, "Archivo Español del Arte" 4, pp. 227-235.

Sebastián López, Santiago (1962), La Escalera Dorada de la Catedral de Burgos, "Goya" 47, pp. 352-356.

Serra Desfilis, Amadeo (2006), El Colegio de España en Bolonia y la arquitectura universitaria del primer renacimiento en Italia y España, en Colomer, José Luis; Serra, Amadeo (coords.), España y Bolonia. Siete siglos de relaciones artísticas y culturales, Madrid, Centro de Estudios Europa Hispánica, pp. 17-30.

Serra Desfilis, Amadeo (2018), Arte y diplomacia en Europa alrededor de 1415. Una aproximación, en Perpignan 1415. Un sommet européen à l'époque du Grand Schisme d'Occident, Münster - Berlín, Lit Verlag, pp. 413-441.

Speranza, Fabio (2001), La escalera dorada de la catedral de Burgos, "Archivo Español de Arte" 293, pp. 19-44.

Tarín y Juaneda, Francisco (1896), La real cartuja de Miraflores (Burgos). Su historia y su descripción, Burgos, Hijos de Santiago Rodríguez.

Teijeira Pablos, María Dolores (2017), De Badajoz a Burgos: Juan Rodríguez de Fonseca en sus catedrales, "Laboratorio de Arte" 29, pp. 53-82.

Teijeira Pablos, María Dolores; Herráez Ortega, María Victoria; Cosmen Alonso, María Concepción (eds.) (2014), Reyes y prelados. La creación artística en los reinos de Castilla y León (1050-1500), Madrid, Sílex.

Teresa León, Tomás (1960), El obispo don Juan Rodríguez de Fonseca: diplomático, mecenas y ministro de Indias, "Hispania Sacra" 13, pp. 251-329.

Valdés Fernández, Manuel (2004), Promotores, arquitectos y talleres en el ocaso de la Edad Media, en La catedral de León en la Edad Media, León, Universidad de León, pp. 373-374.

Vasallo Toranzo, Luis (1992), El arquitecto maestre Martín, en El arte español en épocas de Transición. Actas IX Congreso Nacional de Historia del Arte CEHA, vol. I, León, Universidad de León, pp. 343-351.

Villarroel González, Óscar (2007), Castilla y el Concilio de Siena (14231424): la embajada regia y su actuación, "En la España Medieval" 30, pp. 131-172. 
Villaseñor Sebastián, Fernando (2009), Juan Ruiz de Medina, regio oratori in romana curia, y un conjunto de sus incunables miniados, en El intercambio artístico entre los reinos hispanos y las cortes europeas en la Baja Edad Media, León, Universidad de León, pp. 239-252.

Villaseñor Sebastián, Fernando (2012), Los códices iluminados de Diego de Anaya, fundador del Colegio de San Bartolomé en Salamanca, "Goya" 339, pp. 114-129.

Wethey, Harold E. (1964), Escaleras del primer Renacimiento español, "Archivo Español de Arte" 37/148, pp. 295-305.

Yarza Luaces, Joaquín (1989), Dos Mentalidades, dos actitudes antes las formas artísticas: Diego de Deza y Juan Rodríguez de Fonseca (15001514), en Jornadas sobre la Catedral de Palencia, Valladolid, Universidad de Verano "Casado del Alisal", pp. 105-142.

Yarza Luaces, Joaquín (1993), Los Reyes Católicos: paisaje artístico de una monarquía, Madrid, Nerea.

Yarza Luaces, Joaquín (2003), La nobleza ante el rey. Los grandes linajes castellanos y el arte en el siglo XV, Madrid, El Viso.

Zalama Rodríguez, Miguel Angel (1997), Arquitectura y urbanismo en Medina del Campo en la época de los Reyes Católicos: datos para su estudio, "Boletín del Seminario de Arte y Arqueología" 63, pp. 321-335.

Fecha de recepción del artículo: julio 2020

Fecha de aceptación y versión final: marzo 2021 
